\title{
A Regression-based Approach to Library Fund Allocation
}

\section{By William H. Walters}

While nearly half of all academic libraries use formulas to allocate firm order funds on behalf of particular departments or subject areas, few have adopted systematic methods of selecting or weighting the variables. This paper reviews the literature on library fund allocation, then presents a statistically informed method of weighting and combining the variables in a fund allocation formula. The regression-based method of fund allocation uses current, historical, or hypothetical allocations to generate a formula that excludes the influence of non-relevant variables as well as the influence of arbitrary or non-systematic variations in funding. The resulting fund allocations are based on the principle of equity-the idea that departments with the same characteristics should receive the same allocations.

$\mathrm{M}$ ethods of allocating book funds among academic programs have been discussed in the library literature since 1931, when Randall proposed that each department's allocation should account for the number of titles published in the discipline as well as the cost per title. ${ }^{1}$ Subsequent studies have presented a wide range of fund allocation methods, including some of great sophistication. This paper reviews the literature on library fund allocation, then presents a systematic, statistically informed method of weighting and combining the variables in a fund allocation formula.

The approach described here is most useful for identifying the relationships that underlie a set of previously established allocations-for revealing the formula that best matches the allocation levels set in previous years. It is therefore especially appropriate for institutions that already allocate funds based on historical precedent but without an explicit formula. Other libraries may find the method helpful as a means of evaluating and refining the formulas already in place. Specifically, the regression-based approach to library fund allocation can be used in at least three ways: to generate an allocation formula based on previous years' allocations (in those cases where funds have been allocated based on historical precedent without the use of a formula); to generate an allocation formula based

William H. Walters (william.walters@ millersville.edu) is a Librarian at Millersville (Pa.) University. As of November 2007, he will be Dean of Library Services at Menlo College in Atherton, Calif.

I am grateful for the advice and assistance of Bart Harloe, Esther Isabelle Wilder, and the anonymous referees.

Submitted September 16, 2006; tentatively accepted pending revision November 11, 2006; revised and resubmitted December 7, 2006, and accepted for publication. on subjectively established allocations (in those cases where funds have not been allocated among departments); and to evaluate and refine the formulas already in use (in those cases where the current formulas are unsatisfactory or otherwise in need of modification).

Rational, well-documented methods of fund allocation have several advantages over informal or ad hoc approaches. According to the Association of Research Libraries, allocation formulas and similar techniques promote transparency and the explicit recognition of underlying assumptions, encourage funding practices that are consistent with the library's goals and priorities, ensure that adequate fund monitoring mechanisms are in place, and help the library demonstrate to the university community how its funds are being spent. ${ }^{2}$ Fund allocation formulas also are likely to promote budgetary stability over time (i.e., to reduce the 
likelihood that funding levels will vary unexpectedly from year to year) and to allow departments to predict how changes in curriculum, enrollment, and staffing will influence their library allocations.

Allocation formulas can even be used to influence the behavior of faculty and students. For instance, the formula developed at Washburn University includes a variable representing the use of the library for course-related instruction-a variable that results in higher allocations for those departments that make greater use of the library. ${ }^{3}$ Perhaps most important, however, is the principle of equity-the idea that departments or programs with the same characteristics should get the same amount of money. ${ }^{4}$ The equitable distribution of funds requires the careful selection of funding determinants (variables) that correspond to the goals of the library, an understanding that some determinants should be weighted more heavily than others, and an acknowledgement that changing conditions may require the revision or refinement of the initial allocation formula. ${ }^{5}$

\section{The Fund Allocation Literature}

\section{Past and Current Practices}

Although simple funding formulas have been in use since the 1930s, most libraries have relied on subjective allocation methods until recently. ${ }^{6}$ In the 1920s, departmental library allocations often were set by the college president, sometimes in consultation with the faculty and occasionally with the assistance of the library director. Many institutions simply allocated the same amount of money to each department. ${ }^{7}$ From the 1930s through the 1970s, approximately 70 percent of academic libraries reserved at least some of their book funds for the use of particular departments or programs. ${ }^{8}$

Not all departmental allocations were based on systematic procedures or criteria, however. Even today, many libraries simply set each year's departmental allocation equal to the previous year's allocation, perhaps with across-theboard adjustments for inflation or for changes in the overall library budget. Another common practice is to reduce the allocations of those departments that did not spend all their funds in the previous year. This can lead to rush buying and a possible decline in selection standards at the end of the year. Still other libraries set departmental allocations based on the total funding received by each department from the university. ${ }^{9}$

A review of relevant studies suggests that formulabased allocations first came into prominence in the 1970s. Only eleven significant scholarly papers dealing with fund allocation formulas were published from 1930 to 1969, but thirteen appeared in the 1970s, ten in the 1980s, and sixteen in the 1990s. In recent decades, roughly 40 percent of aca- demic libraries have used formulas to allocate funds. This proportion is likely to be somewhat higher among undergraduate colleges and somewhat lower among research universities. ${ }^{10}$ Of the ten university libraries described in a 1977 Association of Research Libraries report, only one used a formula with a weight for each variable. ${ }^{11}$

While allocation formulas can be applied to all kinds of library materials, relatively few institutions use formulas when allocating budgets for subscriptions or continuing resources. ${ }^{12}$ Formulas are used more often in the allocation of book budgets or other firm order funds. Moreover, many libraries reserve part of the firm order budget for interdisciplinary or nondepartmental acquisitions. The portion of the firm order budget allocated for the use of particular departments is typically around 65 percent, with values ranging from 26 to 89 percent among a set of approximately 200 institutions. $^{13}$

For the most part, librarians who have used fund allocation formulas are satisfied with them. Of the college librarians who reported using allocation formulas in a 1995 survey, 77 percent felt that the formulas they used were equitable. ${ }^{14}$ Another large-scale survey revealed widespread satisfaction among librarians who expressed either positive or negative views of their libraries' fund allocation formulas. ${ }^{15}$ Unfortunately, no published evidence shows librarians' satisfaction with other methods of fund allocation or with book budgets that are not allocated along departmental lines.

\section{Critiques of Formula-Based Fund Allocation}

Several authors have argued that allocation formulas leave no room for the kinds of scholarly judgments that have traditionally been made by subject librarians. For example, Brownson asserts that when an allocation formula is adopted, "the role of expert judgment has thus been withdrawn to the administrator, whose judgment is managing and political rather than scholarly." ${ }^{\prime 6}$ In reality, nothing about the formula-building process privileges administrative authority or excludes scholarly expertise. If anything, fund allocation formulas reduce the likelihood that allocations will be assigned on arbitrary or purely political grounds. While Brownson carefully avoids expressing his own allocation method in algebraic terms, it is nonetheless a formula.

Likewise, Freeman argues that "College librarians should replace formulas with good judgment achieved through (1) continuous discussions with every faculty member; (2) thorough analysis of course syllabi; (3) feedback from librarians conducting bibliographic instruction and from reference librarians handling reference questions; (4) systematic evaluation of faculty publications and research in progress; and (5) information about new courses, majors, and programs." ${ }^{\prime 17}$ Interestingly, every one of these assessment activities can be used as a means of gathering precise, quantitative information for use in an allocation formula. 
Moreover, the development of an allocation formula often provides both the opportunity and the incentives needed for exactly the kinds of evaluative tasks that Freeman mentions. The process of developing an allocation formula lends itself to a project-based framework in which goals, objectives, and expectations are made explicit—a framework that may be especially useful at those institutions where collection assessment activities have not been conducted systematically or rigorously over the years.

A second criticism is that fund allocation formulas lack objectivity - that they give the appearance of scientific rigor without removing the need for subjective decision making. ${ }^{18}$ Strictly speaking, this assertion is correct with regard to regression-based formulas. Although regression analysis is used widely in the sciences, the technique is not inherently scientific. In the context of fund allocation, regression is used primarily to specify the relationships among the variables and only secondarily to discover the true determinants of past or current funding levels. Like conventional fund allocation formulas, regression-based formulas rely on subjective judgment at several stages of the process: in the selection of variables, the compilation or construction of those variables, and the specification of the regression model. The merit of funding formulas is not that they are objective (they are not), but that they are systematic and unbiased - that departments with the same relevant characteristics will receive the same allocations, and that non-relevant characteristics will have no bearing on the results. The ultimate goal, an equitable distribution of funds, requires both the careful selection of funding determinants and the use of a formula-building procedure that results in a systematic and unbiased outcome.

\section{Variables Used in Fund Allocation Formulas}

The development of a fund allocation formula can be viewed as a two-stage process that involves (1) selecting the determinants of funding (the variables to be used in the equation), and (2) deciding how to combine and weight the variables so that the most important factors have a greater role in determining the outcome of the formula.

At least nine papers have described the variables that are potentially useful as determinants of departmental funding levels. ${ }^{19}$ Together, the nine papers present more than sixty distinct variables representing a wide range of departmental, subject-based, and library-specific attributes. Fortunately, several methods can be used to arrive at a more manageable list of potentially relevant variables. One method is to solicit librarians' rankings of the various indicators. For example, Greaves asked librarians at fifty-four colleges and universities to rate the importance of twenty-four variables that might be included in a hypothetical allocation formula. ${ }^{20}$ The variables considered most important, in order, were the adequacy of the library collection within the subject area, the number of new courses offered by the department, the number of students associated with the department as majors or graduate students, the number of recognized disciplines included within the department, the number of undergraduate majors, and total enrollment (credit hours).

A second method of identifying potentially relevant variables is to determine which ones have been used most often in actual fund allocation formulas. Table 1 presents the results of three major surveys of academic libraries along with a content analysis of the variables that appear in fifty-five published allocation formulas. (See appendix A for details.) Together, the values shown in table 1 represent the allocation formulas used at several hundred colleges and universities. The three surveys and the content analysis yield similar results, revealing that certain variables have been used far more often than others. The eight most frequently used variables measure two external factors-the number and cost of the titles published within each disciplinealong with various aspects of the departments' courses (course offerings, course enrollment), personnel (number of faculty, number of students), and library use (circulation, course-related use).

Several authors have presented classifications of the variables that are typically used as determinants of departmental funding levels. ${ }^{21}$ These classifications can be used to help ensure that all relevant factors are included within a fund allocation formula. The most conceptually useful classification groups the variables into three categories: supply (number of new titles published), demand (departmental enrollment, faculty, course offerings, and so on), and cost (average price per title). ${ }^{22}$

Supply, often represented by the number of titles published or reviewed in the previous year, is important because it accounts for the fact that far more books appear in certain subject areas than in others-far more in history than in chemistry, for example. An equitable fund allocation formula might be defined as one that allows each department to acquire a roughly equal percentage of the relevant titles published each year.

Demand variables, such as the number of students, faculty, or courses, are significant because they represent the relative importance of each department or program within the university - not in an educational sense, but in the competition for students and institutional resources. A department offering more courses, serving more students, or supporting more faculty research will presumably require a greater share of the book budget. Most allocation formulas include several demand variables, partly to represent the various dimensions of demand (courses, personnel, library use), and partly because demand-related data are often readily available. 
Table 1. Variables most often used in fund allocation formulas

\begin{tabular}{|c|c|c|c|c|}
\hline Variable & \multicolumn{4}{|c|}{ Data source } \\
\hline Course enrollment (students or credit hours) & 56 & 84 & 53 & 87 \\
\hline Cost of library materials in subject area & 33 & 61 & 62 & 76 \\
\hline Number of majors, minors, graduate students & - & 24 & 41 & 36 \\
\hline Circulation of materials within subject area & 19 & 40 & 51 & 33 \\
\hline Number of courses offered & 31 & 32 & 33 & 29 \\
\hline Number of titles published in subject area & - & 13 & 26 & 20 \\
\hline Number and level of degrees awarded & - & $<5$ & - & 11 \\
\hline Scholarly activity of faculty & 6 & - & - & 9 \\
\hline Previous years' allocations or expenditures & 20 & 8 & - & 9 \\
\hline Interlibrary loan activity & - & $<5$ & - & 5 \\
\hline Adequacy of library collection & 20 & $<5$ & - & 4 \\
\hline
\end{tabular}

Note: Numbers indicate the percentage of formulas that incorporate each variable. See appendix A for further information.

Some authors feel that demand is of primary importance-that library use or circulation should be the sole or chief determinant of departmental library allocations. ${ }^{23}$ For instance, Carrigan argues that "only through use are benefits from investment in library collections realized." 24 This assertion is contrary to economic evidence, which demonstrates that several components of value are independent of use or only indirectly related to it. ${ }^{25}$ User value (the value derived from actual use) can be contrasted with option value (the value associated with potential future use), existence value (the value assigned to the existence of a resource even by those who never intend to use it), and bequest value (the value associated with the maintenance or preservation of a resource for use by others). Moreover, low circulation can represent several factors other than low demand: the unmet need associated with weak or outdated subject collections, the presence of specialized research programs in certain fields, inexpert book selection by library patrons, or subjectspecific publishing practices that encourage photocopying rather than borrowing - the publication of edited collections rather than single-authored monographs, for example.

Finally, the inclusion of a cost variable acknowledges the fact that library materials in some disciplines (art and chemistry, for instance) are more expensive than those in others. The cost variable can therefore help ensure equity in the number of titles purchased.

The most effective fund allocation formula will include not just the best variables, but the best set of variables. The goal is to represent all the appropriate determinants of funding while avoiding the use of multiple variables to represent a single concept. For example, enrollment might be expressed in terms of either students or credit hours, but normally not both. At least one study has shown how factor analysis can be used to select those variables that best represent the underlying characteristics found within a set of many potentially relevant variables. Using data for the South Dakota School of Mines and Technology, McGrath and associates constructed three factors that accounted for 85 percent of the variation within a set of twenty-two variables. ${ }^{26}$ The three factors-course-related demand, research-related demand, and size of the user population-were closely associated with three of the original variables: the total number of credit hours taught within the department, the number of works cited in the graduate theses accepted over a two-year period, and the total number of undergraduate majors and graduate students registered with the department. While not all institutions will benefit from the use of such a sophisticated procedure, the 
technique developed by McGrath and associates is the best way to identify the most representative variables for use in an allocation formula. Four authors provide especially good introductions to factor analysis. ${ }^{27}$

Regardless of the method used to arrive at a set of variables, the choice of variables is ultimately subjective and prescriptive rather than descriptive-not "Which variables are most closely related to current funding levels?" but "Which variables ought to determine how much money is allocated to each department?"

\section{Methods of Weighting and Combining the Variables}

Every fund allocation formula must weight the variables and combine them. Even the simplest approach-listing the variables and adding up their values-implicitly incorporates a system of weights (each variable weighted equally), and a combination method (additive).

Approximately two-thirds of the institutions that use allocation formulas specify unequal weights for the variables. ${ }^{28}$ The weights do matter. Applying the formulas in use at seven different colleges to a single data set representing one particular library, Young found substantial variation in the resulting allocations. ${ }^{29}$ For example, the proportion of the total book budget allocated to Biology varied from 27 to 47 percent when different weights were used. The proportion allocated to geology varied from 4 to 26 percent. Unfortunately, few colleges and universities have systematic procedures for weighting the variables in their allocation formulas. As noted in the guidelines published by the Association of Research Libraries:

There is no generally recognized standard for weighting the [variables]. The weight given to a particular factor in a library will be determined by the goals and resources of the library, and will be tailored to the individual library. Many institutions determine their own weightings; e.g., enrollment in upper division units is worth two of lower division units. Others simply weight all factors in a formula equally. ${ }^{30}$

Many librarians realize the importance of devising a formula consistent with the institution's collection development policy as well as the need to solicit input from stakeholders both inside and outside the library. ${ }^{31}$ Beyond that, however, most appear to use subjective or even arbitrary weights. Of the fifty-four institutions that have published their allocation formulas (appendix A), none provide an explicit rationale for the assignment of weights.

Most fund allocation formulas combine just a few variables. For example, a typical formula might express each department's share (percentage) of the total allocated budget as

$$
(0.4 * \mathrm{e} / \mathrm{E})+(0.3 * \mathrm{~m} / \mathrm{M})+(0.2 * \mathrm{p} / \mathrm{P})+(0.1 * \mathrm{~g} / \mathrm{G})
$$

where

e is the total enrollment in courses offered by the department or program

$\mathrm{E}$ is the sum of the e values, all departments combined

$\mathrm{m}$ is the number of undergraduate majors in the department

$\mathrm{M}$ is the sum of the $\mathrm{m}$ values, all departments combined

$\mathrm{p} \quad$ is the estimated price per title in the relevant subject area

$\mathrm{P}$ is the sum of the $\mathrm{p}$ values, all departments combined

$\mathrm{g}$ is a variable coded 1 if the department offers graduate courses and 0 otherwise

$\mathrm{G}$ is the sum of the $\mathrm{g}$ values, all departments combined.

In this example, undergraduate enrollment, number of majors, average book price, and the presence or absence of graduate programs are weighted 40 percent, 30 percent, 20 percent, and 10 percent, respectively. This formula also illustrates the most common method of combining the variables. Each department's share (of students, courses, library funds, and so on) is expressed as a percentage of the total for the university as a whole. ${ }^{32}$ The equation, a simple additive model, incorporates the assumption that no special relationships exist among the variables - that each contributes directly and proportionally (although not necessarily equally) to the outcome.

While most of the fifty-four libraries listed in appendix A have adopted very simple allocation formulas, at least three modifications to the basic formula can be found in the literature. The first modification is to include one or more variables as negative (undesirable) factors when determining the level of funding each department ought to receive. For instance, the formula

$(0.4 * \mathrm{e} / \mathrm{E})+(0.4 * \mathrm{~m} / \mathrm{M})+(0.2 * \mathrm{p} / \mathrm{P})+(0.1 * \mathrm{~g} / \mathrm{G})-(0.1 * \mathrm{x} / \mathrm{X})$

specifies that departments with higher levels of $\mathrm{x}$ should receive less money than the others. (The $\mathrm{x}$ variable can be anything: new books that never circulate, unspent library funds, faculty who receive poor evaluations, and so on.) 
A second possible modification is to express one or more of the variables in square root or logarithmic form. For instance, modifying the basic formula so that e (course enrollment) equals the square root of undergraduate enrollment produces a formula in which differences in enrollment at the lower end of the scale count much more than differences in enrollment at the higher end of the scale. This approach is especially useful when one or two departments are far larger than the others-when the largest departments ought to get more money, but not in direct proportion to their size. As Lowry states:

A strong case can be made that as the number of credit hours generated increases, particularly in large classes of service courses with many sections, there is a diminishing need to provide book funds to support credit-hour production. Put another way, in the allocation of acquisitions funds, the credit hours produced by the first student . . . should count far more than [those produced by] the 251st student. ${ }^{33}$

A third possible modification is to treat the cost variable separately, as in

$$
[(0.5 * \mathrm{e} / \mathrm{E})+(0.4 * \mathrm{~m} / \mathrm{M})+(0.1 * \mathrm{~g} / \mathrm{G})] * \mathrm{p} / \mathrm{P}
$$

where $\mathrm{P}$ is the average price of a book, all disciplines combined. By introducing the price multiplier outside the rest of the equation, this formula ensures that departments with the same characteristics will be able to purchase the same number of books.

Although the library literature reveals no cases in which institutions have adopted methods of fund allocation based on the principle of resource optimization, several such techniques have been proposed. For example, Goyal describes a fund allocation method based on linear programming, a mathematical technique used to determine the optimal allocation of resources under specified conditions. ${ }^{34}$ Unfortunately, Goyal's method does not provide clear guidance for the construction or weighting of the variables. It requires the subjective determination of "the importance which society attaches to the work of the department" and "the importance which the university gives to the work of the department" - judgments that must be made outside the linear programming framework. ${ }^{35}$ Likewise, the economic model developed by Gold relies on the subjective assessment of the extent to which students' library use benefits the university. ${ }^{36}$ Gold's method also has been criticized for its emphasis on economic efficiency rather than equity among departments. ${ }^{37}$ More recent applications of linear goal programming avoid the use of weights but do require the specification and ranking of the library's goals and priorities before the analysis is performed ${ }^{38}$

\section{A Regression-based Approach}

Multiple regression, a standard statistical technique, can be used to assign weights to a set of variables so that the resulting formula produces results consistent with a set of predetermined values. For instance, regression can be used to assign weights to a set of supply, demand, and cost variables so that the resulting allocations are consistent with previous years' fund allocations. Within this context, regression analysis can be used in at least three ways:

- to construct an allocation formula based on previous years' allocations; this is appropriate for libraries that already assign funds to departments, but without the use of an explicit formula,

- to construct an allocation formula based on subjectively established allocations; this is appropriate for libraries that have never allocated funds to particular departments but that have nonetheless determined (at least in general terms) the amount that each department should receive, and

- to evaluate or refine existing allocation formulas or procedures.

The refinement of existing formulas or procedures can take several forms. For instance, regression can be used to modify a set of allocations so that they reflect the influence of only those variables that have been explicitly selected. This procedure removes the unique influence of any other variables - those excluded from the equation-as well as any random or non-systematic variations in funding. Likewise, regression can be used to create a new formula that maintains allocations similar to those used in previous years, but based on a new set of variables - variables that are more appropriate or more readily operationalized than those that were used in the past.

Regression analysis has been used in at least three previous fund allocation studies. More than thirty years ago, Pierce used stepwise log-linear regression to create an innovative book use variable incorporating only those components of circulation that could not be attributed to collection size or previous years' acquisitions. ${ }^{39}$ Pierce did not use regression to weight or combine the variables in his formula, however. Similarly, Brownson constructed a conventional allocation formula, then used regression to examine the relationships among the variables. ${ }^{40} \mathrm{He}$ found, among other things, that past years' expenditures are closely related to current research activity but not closely related to perceived collection strength.

Finally, at least one university has used regression in the construction of a fund allocation formula. ${ }^{41}$ The formula, incorporating seven variables (undergraduate majors, graduate students, faculty, courses taught, library circulation, current collection size, and average book price), is presented 
only briefly, however. The university is not identified, and just one sentence of commentary is provided: "The formula was derived from a regression analysis using over ten years of historical data." 42

The process used to arrive at a regression-based allocation formula is the same regardless of the reasons for undertaking the analysis. The regression-based approach to fund allocation has five essential steps:

1. Select a dependent variable that represents current, past, or hypothetical funding levels.

2. Identify a set of potential explanatory variables-factors that ought to influence the amount of money spent on behalf of each department.

3. Select the final set of variables for use in the regression analysis. (Compile and prepare the data, then examine the correlations among the explanatory variables. Decide which ones to include.)

4. Perform the regression analysis using a statistical package, such as SPSS, MINITAB, or SAS.

5. Interpret the results.

This approach will result in a fund allocation formula that is a weighted combination of the variables included in the analysis.

\section{Step 1: Select a Dependent Variable}

The regression-based approach requires not only a set of variables for inclusion in the allocation formula, but a separate variable (called a dependent variable) that represents current, past, or hypothetical funding levels. For libraries that have previously allocated funds for the use of particular departments, this variable can be the most recent set of allocations or the average of several years' allocations. For libraries with no history of departmental fund allocation, this variable must be developed outside the regression framework based on the professional expertise of the librarians, faculty, and staff.

Although the initial assignment of subjectively determined allocations is no more systematic than the ad hoc development of a fund allocation formula, the regressionbased approach is appropriate whenever the individuals who allocate funds have more confidence in their ability to assign allocations to departments than in their ability to develop a new formula from scratch. Even though the initial allocations are assigned on subjective grounds before the analysis is undertaken, the regression procedure results in a new set of allocations that incorporate only the influence of those variables included in the equation. Any arbitrary or non-systematic variation in the original allocations will be excluded from the final allocations that emerge from the regression-based procedure.

\section{Step 2: Identify a Set of Potential Explanatory Variables}

For the explanatory variables - those that will be included in the fund allocation formula-several methods of selection can be used. As discussed earlier, most libraries' allocation formulas include variables representing external factors (the number and cost of the titles published within each discipline) as well as internal, institutional characteristics, such as courses (course enrollment, course offerings), personnel (number of faculty, number of students), and library use (circulation, course-related use). While previous research and practice provide guidance in the selection of variables, the decision to include or exclude a particular variable is subjective and likely to depend on local conditions.

Ideally, the explanatory variables will reflect the situation that ought to prevail rather than the historical conditions that are most likely to have resulted in the current fund allocations. Because practical considerations cannot be ignored, most allocation formulas include variables that are "resistant to deliberate local manipulation" and that can be represented adequately by data compiled within the library or elsewhere on campus. ${ }^{43}$ Data for at least ten of the fourteen variables shown in table 1 are available at most universities from the registrar's office, the office of institutional research, or the library's own acquisitions, circulation, and interlibrary loan systems. The number of titles published, cataloged, or reviewed in each subject area can be estimated from data presented in the American Book Publishing Record, Books in Print, the Bowker Annual Library and Book Trade Almanac, Choice, Publishers Weekly, or WorldCat, or from vendors' approval plan records. One advantage of using Choice or approval plan records is that they cover only those titles that are appropriate for academic libraries. The cost of library materials can be estimated from many of the same sources, or calculated from internal library records. Shreeves lists ten sources of price data. ${ }^{44}$

Not every potentially relevant variable should be included in the regression analysis, however. There are at least three reasons to limit the number of variables: to avoid specification error (the exclusion of important variables or the inclusion of irrelevant variables), to avoid unnecessary work in compiling the data, and to achieve more robust resultsresults that are less likely to vary as a result of minor changes in the model specification or the data. With regard to robustness, many statisticians recommend using no more than one-tenth as many variables as cases. In practice, however, a less stringent standard is often applied. For a set of thirty or thirty-five departments, the use of five or six variables is a reasonable compromise between the need to include all the important determinants of funding and the need to limit the number of variables relative to the number of cases.

Figure 1 describes the explanatory variables that might be considered for inclusion in the fund allocation formula 


\begin{abstract}
Variable
c

$\mathrm{h}$

f

$\mathrm{p}$

\section{Definition}

Estimated number of relevant titles published in the subject area each year. Equal to twice the number of approval plan books and slips received over a 26-week period (May 14 to November 5, 2003). Includes items not kept or purchased. Excludes interdisciplinary and multidisciplinary titles.

Number of distinct courses offered in the Fall 2004 semester plus the number of distinct courses offered in the Spring 2005 semester. Excludes non-credit courses and courses without scheduled meeting times.

Total enrollment in courses offered by the department or program, 2004-05 academic year; the sum of individual course enrollments. Courses formally sponsored by more than one department are attributed partly (equally) to each sponsoring department.

Number of senior projects and master's theses submitted in the 2002-03, 2003-04, and 2004-05 academic years.

Number of regular faculty positions plus one-fourth the number of adjunct instructors and other part-time academic staff not on the faculty list, 2004-05 academic year.

Number of undergraduate majors and graduate students in the department, Fall 2004. Students with more than one major are counted more than once. Students registered for joint majors (Economics \& Mathematics, Environmental Studies \& Biology, etc.) are counted partly (equally) for each department.

Estimated price per title in the relevant subject area, 2004-05 academic year. Based on approval plan data for May 2003 to November 2003, inflated by 3 percent.
\end{abstract}

Figure 1. Variables considered for inclusion in a regression-based fund allocation formula

of a typical college library. They include six of the seven variables most often used in actual fund allocation formulas (table 1) as well as an indicator of student research activity-the number of senior projects and master's theses completed. Each variable represents a particular aspect of the external or internal environment. Specifically, the seven variables correspond to the three categories identified by Sweetman and Wiedemann:

- supply: $\mathrm{t}$ (number of titles published);

- demand: c (number of courses offered), e (course enrollment), h (number of projects and theses completed), $f$ (number of faculty), and $m$ (number of majors and graduate students); and

- cost: $\mathrm{p}$ (price per title). ${ }^{45}$

\section{Step 3: Select the Final Set of Variables}

The example analysis presented in this paper is based on data for St. Lawrence University, a small liberal arts college in Canton, New York. Data for the seven variables shown in figure 1 are presented in appendix B. If the procedures described in this paper are carried out properly using those data, the results should be identical to those reported here.

While a regression analysis might be undertaken with all seven variables, a more reliable technique is to first identify and exclude those explanatory variables that are closely related to the other variables in the set. The use of closely related variables can result in two related problems: specification error and multicollinearity. ${ }^{46}$ Broadly speaking, the unique impact of a particular variable (and the importance of that variable as a determinant of fund allocation levels) is more difficult to ascertain when the variable is closely related to the others in the equation. No absolute standard exists for identifying closely related variables, although any explanatory variable correlated with two or more others at the 0.80 level or higher is likely to warrant further examination. The correlations among the explanatory variables can be assessed using Excel (the CORREL function), SPSS (Analyze-Correlate-Bivariate), MINITAB (Stat-Basic Statistics-Correlation), or another statistical package.

In the example analysis, variables $\mathrm{m}$ (majors), e (course enrollment), $\mathrm{f}$ (faculty), and $\mathrm{h}$ (projects and theses) are all interrelated (see table 2). Closer examination reveals that all the correlations with absolute values greater than 0.80 can be eliminated through the exclusion of two variables: $m$ and either e or $\mathrm{f}$.

The $\mathrm{m}$ (majors) variable should be excluded for two reasons. First, it is closely related to at least three other explanatory variables: e (course enrollment), h (projects and theses), and $f$ (faculty). Second, data on the number of majors are especially likely to be adversely affected by measurement error. Many students change their majors, others have no declared major despite their strong interest in a particular field, and at least some intend to graduate with a major different than the one for which they are officially enrolled.

Although neither e (course enrollment) nor $\mathrm{f}$ (faculty) must be excluded due to the correlations shown in table 2 , variable e should probably be excluded due to the characteristics of the particular institution represented by these data. Specifically, St. Lawrence University is a small college 
Table 2. Correlations among the variables considered for inclusion in the fund allocation formula

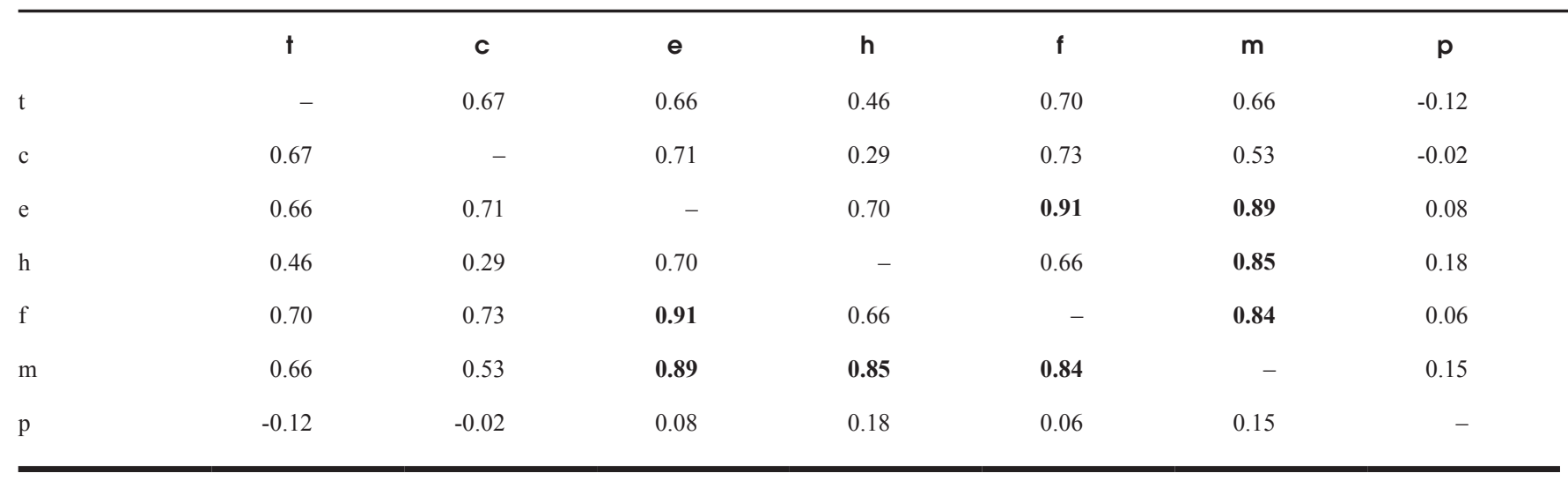

Note: Correlations with absolute values greater than 0.80 are shown in bold.

where many of the stronger or more distinctive departments do not have high course enrollments. On the other hand, variable $\mathrm{f}$ (faculty) ought to be included in the equation, as the number of faculty tends to correspond to the number of distinct teaching or research areas represented within each department. At St. Lawrence, faculty often are hired to cover specific disciplinary areas that are likely to require unique library resources.

Variables $\mathrm{t}$ (number of titles published), c (number of courses offered), and $\mathrm{p}$ (price per title) are only weakly related to the other explanatory variables (see table 2). This is not unexpected, as variables $t$ and $p$ represent supply and cost rather than demand. The absence of strong relationships between variable $\mathrm{c}$ and the other demand variables indicates that the number of courses represents a component of demand that is essentially unrelated to the number of students, faculty, or research projects.

\section{Step 4: Perform the Regression Analysis}

Regression analysis reveals the relationships between a single dependent variable and a set of explanatory variables (also called independent or predictor variables). In this example, the dependent variable is the amount allocated for monographic firm orders in a recent year (variable a) and the explanatory variables are those that will be included in the fund allocation formula: $t$ (number of titles published), $\mathrm{c}$ (number of courses offered), $\mathrm{h}$ (number of projects and theses completed), $f$ (number of faculty), and $p$ (price per title) (see figure 1 for details). The regression equation can be expressed in the form

$$
\mathrm{a}=\left(\mathrm{w}_{\mathrm{t}} * \mathrm{t}\right)+\left(\mathrm{w}_{\mathrm{c}} * \mathrm{c}\right)+\left(\mathrm{w}_{\mathrm{h}} * \mathrm{~h}\right)+\left(\mathrm{w}_{\mathrm{f}} * \mathrm{f}\right)+\left(\mathrm{w}_{\mathrm{p}} * \mathrm{p}\right)+\mathrm{b}
$$

where the $\mathrm{w}$ values are the weights associated with each variable. The $b$ term at the end of the equation is a constant-a specific, fixed value to be added to each department's allocation. The constant, also called a y-intercept, emerges from the regression analysis; it is not specified in advance. While most statistical software packages will let the user specify a y-intercept of zero, the inclusion of a non-zero constant will produce a regression equation that better fits the data.

The regression procedure can be understood best through an example involving a single explanatory variable. Figure 2 shows the regression line corresponding to the equation

$$
\mathrm{a}=(0.00166 * \mathrm{t})+1.84347
$$

where $\mathrm{a}$ is the allocation for each department and $\mathrm{t}$ is the number of titles published in each corresponding subject area. If the number of titles published were the only factor influencing the departmental allocations, then one would expect each dot (each department) to fall somewhere along the regression line. The allocation for any particular department could then be determined by finding the number of titles on the horizontal axis, finding the same place on the regression line, and reading off the allocation on the vertical axis. In fact, however, the allocation for each department is influenced by several factors other than the number of titles published. Consequently, most of the dots are above or below the regression line rather than right on it.

Nonetheless, the regression line and the corresponding equation have been calculated to most effectively represent the linear relationship between the two variables. The regression line is the line that most closely conforms to the pattern of dots. Specifically, it is the line that minimizes the sum of the squared vertical distances between the dots (which represent the actual situation) and the line itself (which represents the situation that would exist if the number of titles published were the only determinant of fund allocation levels). Figure 2 is a relatively simple example 
showing just two variables-one dependent variable and one explanatory variable. With three variables, the graph would need to be represented in three dimensions, and the line would become a plane. With six variables, the graph would need six dimensions. While the six-variable regression cannot be shown geometrically, the corresponding equation can be solved algebraically.

The data for the example regression appear in appendix $B$. When regression is used to construct an allocation formula, one does not need to express each variable as a percentage of the total for the university as a whole. The inclusion of one or more variables in square root or logarithmic form may sometimes be appropriate, however. As noted earlier, such transformations can be used to specify a non-linear relationship between a particular variable (enrollment, for example) and fund allocation levels. In most applications of regression, the goal is to identify the model that best fits the observed data; the best-fitting model (linear or otherwise) is selected. When regression is used to construct a fund allocation formula, however, the goal is to produce an acceptable model that is consistent with the library's objectives. If there is good reason to believe that the largest departments should not receive allocations in proportion to their size, then it is appropriate to incorporate that stipulation into the regression equation through a transformation of the relevant variable- even if the resulting model does not provide the best possible fit. The assumptions underlying regression, and the effects of intentionally or unintentionally violating those assumptions, are described most clearly by Achen, Berry, Kahane, and Lewis-Beck. ${ }^{47}$

To conduct the regression analysis, first enter data for all the relevant variables into SPSS, MINITAB, or another statistical package. (Appendix B shows how the data should be arranged.) Next, choose the type of analysis and specify the variables. In SPSS, select Analyze-Regression-Linear; in MINITAB, select Stat-Regression-Regression. The fund allocation variable is the dependent or response variable; the other variables are independent or predictor variables. The default analysis options will not need to be altered.

\section{Step 5: Interpret the Results}

In the fund allocation context, the most important statistics to emerge from the analysis are the unstandardized regression coefficients. These can be found near the end of the SPSS output (in the Coefficients table-the column labeled B) or near the top of the MINITAB output (the column labeled Coef). In SPSS, click on each value in the Coefficients table to see additional decimal places. Because each coefficient is a weight in the fund allocation formula, the coefficients can simply be inserted into the standard regression equation. For the data shown in appendix B, the regression equation is

$$
\begin{aligned}
& \mathrm{a}=(0.00154 * \mathrm{t})+(0.00602 * \mathrm{c})+(0.01561 * \mathrm{~h})+ \\
& (0.00518 * \mathrm{f})+(0.06251 * \mathrm{p})-1.56631 .
\end{aligned}
$$

This formula can be used to calculate an allocation for each department. It also can be used to show how a change in the number of course offerings, senior projects, or faculty would affect each department's library allocation. For example, each senior project or master's thesis $(h)$ brings in an additional 0.01561 percent of the allocated firm order budget. With a total allocated budget of $\$ 200,000$, each senior project or thesis represents an additional $\$ 31.22$ in departmental library funding. Under the same assumptions:

- Each new title published in the relevant subject area (t) brings an additional $\$ 3.08$.

- Each new departmental course (c) brings an additional $\$ 12.04$.

- Each new faculty position (f) brings an additional $\$ 10.36$.

- An increase of $\$ 1$ in average cost per title (p) brings an additional $\$ 125.02$.

In comparison with most fund allocation formulas, this particular formula emphasizes external factors (the number and cost of the books available for purchase) rather than internal factors, such as the number of courses and faculty associated with each department. The formula is "correct" because it accurately represents the implicit and previously

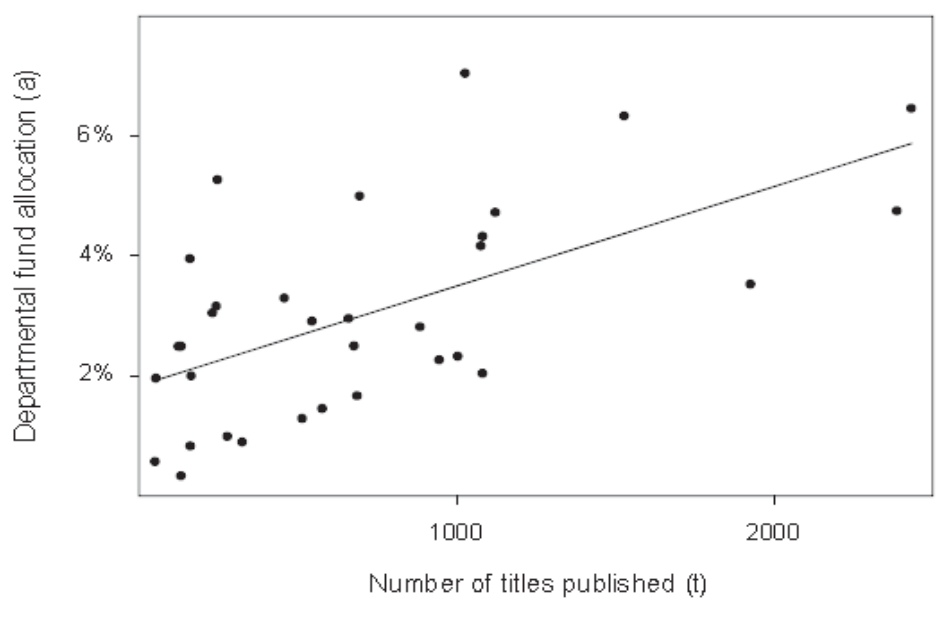

Figure 2. Regression line showing the relationship between the number of titles published and the departmental fund allocation 
unspecified variables and weights on which earlier allocations were based. Many librarians would argue that the number of courses and faculty should have a greater impact on departmental allocations, and an adjustment to reflect that view would be entirely legitimate. However, any such adjustment would represent an intentional modification of the procedure (the implicit formula) on which earlier allocations were based - a fact that may be important when justifying the change to constituents outside the library.

A second important statistic to emerge from the regression analysis is the adjusted $R^{2}$ value. This value ranges from 0 to 1 , but is typically within the 0.3 to 0.7 range. A high $\mathrm{R}^{2}$ value indicates that the regression equation fits the data well-that the allocation levels that emerge from the regression analysis are similar to the previous or hypothetical allocations (those represented by the dependent variable). In contrast, a low $\mathrm{R}^{2}$ value indicates a relatively poor fit - that the new allocations are substantially different from the previous or hypothetical allocations.

A low $\mathrm{R}^{2}$ value does not mean that the regression-based formula is deficient or unreliable, however. In fact, it indicates only that the original fund allocations were established through a non-systematic process, or a process based on factors that are no longer relevant and therefore not found in the regression equation. That is, a low $\mathrm{R}^{2}$ value shows that the original fund allocations were inequitable (in the sense that departments with similar characteristics could receive different allocations) and that a more systematic method of fund allocation - the regression-based method, for instance-is likely to be an improvement over past practices. For St. Lawrence University, the adjusted $R^{2}$ value is 0.44 . This indicates that 44 percent of the interdepartmental variation in the original fund allocation levels can be attributed to the explanatory variables included in the regression equation.

Guides to regression analysis often emphasize significance tests, which are used to make generalizations about a population based on data for a sample. Significance tests are not especially meaningful in the fund allocation context, as the entire population of interest (the set of all the departments at a particular institution) is included within the data used in the analysis.

\section{Commentary}

Regression removes the influence of non-systematic variations in funding as well as the influence of variables not included in the equation. Consequently, the allocations that result from a regression-based formula may be appreciably different from those used in the past. This is most likely to occur among the smaller academic departments, especially when the $\mathrm{R}^{2}$ value is low. In an analytical sense, this is not a problem; it represents the natural result of an approach that treats similar departments similarly. Realistically, however, reductions in funding are not likely to be greeted enthusiastically by the departments affected.

One method of dealing with the problem is to set aside a portion of the allocated budget for distribution in accordance with the earlier allocation procedure, gradually increasing the proportion of the budget that is allocated in accordance with the new formula. Another approach is to ask for special short-term funding to ensure that no department experiences a sudden reduction in its library allocation. These approaches to implementation are not specific to regression-based fund allocation methods. For example, the conventional formula adopted in the mid-1980s by Ohio University was put into place gradually so that no department's allocation was reduced. ${ }^{48}$

Two strategies might be used to encourage the acceptance of a regression-based approach to fund allocation. The first is to introduce regression strictly as an analytical technique-as a means of evaluating the extent to which each variable influences current funding levels and as a means of identifying those departments with actual allocations substantially higher or lower than the calculated values. This strategy, which can be adopted without external support or collaboration, is especially appropriate when stakeholders outside the library are unlikely to accept the procedure on its own merits-when they are likely to evaluate its acceptability primarily in terms of its impact on their own departments. This strategy also is appropriate when the regression analysis is based not on actual allocations, but on a set of hypothetical allocations established subjectively by the librarians. When regression is used primarily for analytical purposes, the resulting formula (with or without subsequent adjustments) can be presented to faculty and administrators without reference to the means by which it was developed.

A second strategy is to introduce regression right from the start as a method of allocating funds - to gain support for the procedure before the analysis is conducted so that the results will be less subject to criticism afterward. This approach is especially useful when a high proportion of faculty and administrators are familiar with regression analysis and willing to participate in the most important part of the process - the selection of relevant variables. Because the regression-based formula still may require modification, the interested parties may want to agree beforehand about the appropriate procedure for adjusting the formula. In particular, the legitimate reasons for adjustment (disciplinary accreditation requirements, for example) should be specified in advance.

If the regression-based approach to fund allocation proves acceptable, subsequent years' allocations can be set by using the same proportional allocation of funds each year, or by using the same formula with new (current) data. If the 
second approach is adopted, the new departmental allocations will not necessarily total 100 percent, so they may need to be increased or decreased proportionally (multiplied or divided by a constant). With either approach, the formula itself should be re-evaluated after several years.

The regression-based method of fund allocation relies on a statistical technique that has been in use for several decades. At the same time, the particular application of regression presented in this paper has not been tested through implementation and practice. Further investigation is needed to assess the effectiveness of the method at various types of institutions and to determine the usual range of variation in the formulas developed at particular colleges and universities.

The same regression-based approach can be used for strictly analytical purposes-to examine the broader relationships underlying various fund allocation strategies. Several questions might be considered. For example, are the fund allocation strategies adopted by major research universities more strongly affected by external factors than those adopted by liberal arts colleges? Does the regressionbased method of fund allocation produce systematically high or low allocations for certain fields of study or certain kinds of academic departments? One advantage of the regression-based approach is that it can be used to evaluate the determinants of funding even at those institutions that do not use explicit fund allocation formulas.

\section{References}

1. William M. Randall, "The College-Library Book Budget," Library Quarterly 1, no. 4 (Oct. 1931): 421-35.

2. Association of Research Libraries, The Allocation of Materials Funds in Academic Libraries, SPEC Kit 36 (Washington, D.C.: Association of Research Libraries, 1977).

3. Jane H. Tuten and Beverly Jones, eds., Allocation Formulas in Academic Libraries, CLIP Note 22 (Chicago: Association of College \& Research Libraries, 1995).

4. Edward Shreeves, ed., Guide to Budget Allocation for Information Resources, Collection Management and Development Guides, no. 4 (Chicago: ALA, 1991); Tuten and Jones, Allocation Formulas in Academic Libraries.

5. Mollie Niemeyer et al., "Balancing Act for Library Materials Budgets: Use of a Formula Allocation," Technical Services Quarterly 11, no. 1 (1993): 43-60.

6. Charles M. Baker, "Apportioning of College and University Library Book Funds," Library Journal 57, no. 4 (Feb. 15, 1932): 166-67; Randall, "The College-Library Book Budget."

7. Floyd W. Reeves and John Dale Russell, "The Administration of the Library Budget," Library Quarterly 2, no. 3 (July 1932): 268-78.

8. Baker, "Apportioning of College and University Library Book Funds"; John M. Budd, "Allocation Formulas in the Literature: A Review," Library Acquisitions: Practice of Theory 15, no. 1 (Spring 1991): 95-107; F. Landon Greaves Jr., The Allocation Formula As a Form of Book Fund
Management in Selected State-Supported Academic Libraries (Ph.D. dissertation, Florida State Univ., 1974).

9. Bette Dillehay, "Book Budget Allocation: Subjective or Objective Approach," Special Libraries 62, no. 12 (Dec. 1971): 509-14; David C. Genaway, "PBA: Percentage Based Allocation for Acquisitions: A Simplified Method for the Allocation of the Library Materials Budget," Library Acquisitions: Practice \& Theory 10, no. 4 (Winter 1986): 287-92.

10. John M. Budd and Kay Adams, "Allocation Formulas in Practice," Library Acquisitions: Practice \& Theory 13, no. 4 (Winter 1989): 381-90; Geoffrey Ford, "Finance and Budgeting," in Collection Management in Academic Libraries, ed. Clare Jenkins and Mary Morley, 21-56 (Brookfield, Vt.: Gower, 1991); Tuten and Jones, Allocation Formulas in Academic Libraries.

11. Association of Research Libraries, The Allocation of Materials Funds.

12. Donna Packer, "Acquisitions Allocations: Fairness, Equity, and Bundled Pricing," portal: Libraries and the Academy 1, no. 3 (July 2001): 209-24.

13. David C. Genaway, "The Q Formula: The Flexible Formula for Library Acquisitions in Relation to the FTE Driven Formula," Library Acquisitions: Practice \& Theory 10, no. 4 (Winter 1986): 293-306; James H. Richards Jr., "Allocation of Book Funds in College Libraries," College \& Research Libraries 14, no. 4 (Oct. 1953): 379-80; Mary C. Scudder, "Using Choice in an Allocation Formula in a Small Academic Library," Choice 24, no. 10 (June 1987): 1506-11; Tuten and Jones, Allocation Formulas in Academic Libraries.

14. Tuten and Jones, Allocation Formulas in Academic Libraries.

15. Budd and Adams, "Allocation Formulas in Practice."

16. Charles W. Brownson, "Modeling Library Materials Expenditure: Initial Experiments at Arizona State University," Library Resources \& Technical Services 35, no. 1 (Jan. 1991): 88 .

17. Michael S. Freeman, "Allocation Formulas As Management Tools in College Libraries: Useful or Misapplied?" in Collection Development in College Libraries, ed. Joanne Schneider Hill, William E. Hannaford Jr., and Ronald H. Epp, 71-77 (Chicago: ALA, 1991), 75.

18. Budd and Adams, "Allocation Formulas in Practice."

19. Baker, "Apportioning of College and University Library Book Funds"; Donald Coney, "An Experimental Index for Apportioning Departmental Book Funds for a University Library," Library Quarterly 12, no. 3 (July 1942): 422-28; Ralph E. Ellsworth, "Some Aspects of the Problem of Allocating Book Funds among Departments in Universities," Library Quarterly 12, no. 3 (July 1942): 486-94; Genaway, "The Q Formula”; William E. McGrath, Ralph C. Huntsinger, and Gary R. Barber, "An Allocation Formula Derived From a Factor Analysis of Academic Departments," College \& Research Libraries 30, no. 1 (Jan. 1969): 51-62; Jasper G. Schad, "Allocating Materials Budgets in Institutions of Higher Education,” Journal of Academic Librarianship 3, no. 6 (Jan. 1978): 328-32; Reeves and Russell, "The Administration of the Library Budget"; Shreeves, Guide to Budget Allocation; Norman E. Tanis, "The Departmental Allocation of Library 
Book Funds in the Junior College: Developing Criteria," Library Resources \& Technical Services 5, no. 4 (Fall 1961): 321-27.

20. Greaves, The Allocation Formula.

21. Coney, "An Experimental Index"; McGrath et al., "An Allocation Formula"; Schad, "Allocating Materials Budgets"; Peter Sweetman and Paul Wiedemann, "Developing a Library Book-Fund Allocation Formula," Journal of Academic Librarianship 6, no. 5 (Nov. 1980): 268-76; Tanis, “The Departmental Allocation."

22. Sweetman and Wiedemann, "Developing a Library BookFund Allocation Formula."

23. Anish Arora and Diego Klabjan, "A Model for Budget Allocation in Multi-Unit Libraries," Library Collections, Acquisitions \& Technical Services 26, no. 4 (Winter 2002): 42338; Dennis P. Carrigan, "Improving Return on Investment: A Proposal for Allocating the Book Budget," Journal of Academic Librarianship 18, no. 5 (Nov. 1992): 292-97; Neale S. Grunstra, The Development of Library Resource Allocation Procedures in Higher Education Based on the Analysis of Materials Utilization (Ph.D. dissertation, Univ. of Pittsburgh, 1976); Andrea C. Hoffman, An Investigation of a Predicted Use Approach to Resource Allocation, D.A. field study, Simmons College, 1978; William E. McGrath, "A Pragmatic Book Allocation Formula for Academic and Public Libraries With a Test for Its Effectiveness," Library Resources d Technical Services 19, no. 4 (Fall 1975): 356-69.

24. Carrigan, "Improving Return on Investment," 293.

25. Hans-Jörg Blöchliger, "Exploratory Framework," in The Contribution of Amenities to Rural Development, ed. HansJörg Blöchliger, 7-21 (Paris: Organisation for Economic Co-operation and Development, 1994); Douglas B. Diamond Jr. and George S. Tolley, "The Economic Roles of Urban Amenities," in The Economics of Urban Amenities, ed. Douglas B. Diamond Jr. and George S. Tolley, 3-54 (New York: Academic Pr., 1982).

26. McGrath et al., "An Allocation Formula."

27. Dennis Child, The Essentials of Factor Analysis (New York: Holt, Rinehart, and Winston, 1970); Jae-On Kim and Charles W. Mueller, Factor Analysis: Statistical Methods and Practical Issues, Quantitative Applications in the Social Sciences 14 (Beverly Hills, Calif.: Sage Publ., 1978); Jae-On Kim and Charles W. Mueller, Introduction to Factor Analysis: What It Is and How to Do It, Quantitative Applications in the Social Sciences 13 (Beverly Hills, Calif.: Sage Publ., 1978); Paul Kline, An Easy Guide to Factor Analysis (New York: Routledge, 1994).

28. Tuten and Jones, Allocation Formulas in Academic Libraries.

29. Ian R. Young, "A Quantitative Comparison of Acquisitions Budget Allocation Formulas Using a Single Institutional Setting," Library Acquisitions: Practice \& Theory 16, no. 3 (Autumn 1992): 229-42.

30. Association of Research Libraries, The Allocation of Materials Funds, 9.

31. Eugene Bourgeois et al., "Faculty-Determined Allocation Formula at Southwest Texas State University," Collection
Management 23, no. 1/2 (1998): 113-23; Brownson, "Modeling Library Materials Expenditure"; Lisa B. German and Karen A. Schmidt, "Finding the Right Balance: Campus Involvement in the Collections Allocation Process," Library Collections, Acquisitions \& Technical Services 25, no. 4 (Winter 2001): 421-33.

32. Genaway, "The Q Formula"; Charles B. Lowry, "Reconciling Pragmatism, Equity, and Need in the Formula Allocation of Book and Serial Funds," College \& Research Libraries 53, no. 2 (March 1992): 121-38.

33. Lowry, "Reconciling Pragmatism," 126.

34. S. K. Goyal, "Allocation of Library Funds to Different Departments of a University: An Operational Research Approach," College \& Research Libraries 34, no. 3 (May 1973): 219-22.

35. Ibid., 220.

36. Steven D. Gold, "Allocating the Book Budget: An Economic Model," College \& Research Libraries 36, no. 5 (Sept. 1975): 397-402.

37. Joseph J. Kohut, "Allocating the Book Budget: A Model," College \& Research Libraries 35, no. 3 (May 1974): 19299; Joseph J. Kohut and John F. Walker, "Allocating the Book Budget: Equity and Economic Efficiency," College o Research Libraries 36, no. 5 (Sept. 1975): 403-10.

38. Kenneth Wise and D. E. Perushek, "Goal Programming As a Solution Technique for the Acquisitions Allocation Problem," Library \& Information Science Research 22, no. 2 (June 2000): 165-83; Kenneth Wise and D. E. Perushek, "Linear Goal Programming for Academic Library Acquisitions Allocations," Library Acquisitions: Practice \& Theory 20, no. 3 (Autumn 1996): 311-27.

39. Thomas John Pierce, The Economics of Library Acquisitions: A Book Budget Allocation Model for University Libraries (Ph.D. dissertation, Univ. of Notre Dame, 1976).

40. Brownson, "Modeling Library Materials Expenditure."

41. Budd and Adams, "Allocation Formulas in Practice."

42. Ibid., 388 .

43. McGrath et al., "An Allocation Formula," 60.

44. Shreeves, Guide to Budget Allocation.

45. Sweetman and Wiedemann, "Developing a Library BookFund Allocation Formula."

46. Christopher H. Achen, Interpreting and Using Regression, Quantitative Applications in the Social Sciences 29 (Beverly Hills, Calif.: Sage Publ., 1982); William D. Berry, Understanding Regression Assumptions, Quantitative Applications in the Social Sciences 92 (Newbury Park, Calif.: Sage Publ., 1993); Leo H. Kahane, Regression Basics (Thousand Oaks, Calif.: Sage Publ., 2001); Michael S. LewisBeck, Applied Regression: An Introduction, Quantitative Applications in the Social Sciences 22 (Beverly Hills, Calif.: Sage Publ., 1980).

47. Ibid.

48. Kent Mulliner, "The Acquisition Allocation Formula at Ohio University," Library Acquisitions: Practice \& Theory 10, no. 4 (Winter 1986): 315-27. 


\section{Appendix A. Data Sources for Table 1}

Table 1 presents the results of three major surveys of academic libraries (Budd and Adams 1989; Greaves 1974; Tuten and Jones 1995) along with a content analysis of the variables that appear in fifty-five published allocation formulas. The fifty-five published formulas represent fifty-four colleges and universities.

\section{Institution}

Arizona State University

Arkansas Technical University

Augusta College

Aurora University

Baker University

Berry College

California University of Pennsylvania

Carleton College

Catawba College

Central Missouri State University

Colorado State University

Columbia Union College

Curtin Institute of Technology

Davidson College

Elon College

Florida Gulf Coast University

Fort Valley State College

George Mason University

Georgia College

Goucher College

Illinois Wesleyan University

Keuka College

Lander College

Lynchburg College

Lyndon State College

Manchester College

Methodist College

Mount St. Mary's College and Seminary

Notre Dame University of Nelson

Ohio University

Olivet Nazarene University

Shepherd College

Simon Fraser University

South Dakota School of Mines and Technology

Southern Arkansas University

Southwest Texas State University

Southwestern Oklahoma State University

St. John Fisher College

St. Mary's University

St. Norbert College

Stetson University

SUNY College at Potsdam

Transylvania University

Union University

University of Colorado

University of Constance

University of South Carolina at Aiken

University of Southwestern Louisiana

\section{Source}

Brownson (1991)

Tuten and Jones (1995)

Tuten and Jones (1995)

Tuten and Jones (1995)

Tuten and Jones (1995)

Tuten and Jones (1995)

Tuten and Jones (1995)

Richards (1953)

Tuten and Jones (1995)

Brookshier and Littlejohn (1990); Niemeyer et al. (1993)

Association of Research Libraries (1977)

Tuten and Jones (1995)

Allen and Tat (1987)

Tuten and Jones (1995)

Jones and Keller (1993)

Donlan (2006)

Tuten and Jones (1995)

Rein et al. (1993)

Tuten and Jones (1995)

Falley (1939)

Tuten and Jones (1995)

Tuten and Jones (1995)

Tuten and Jones (1995)

Scudder (1987)

Tuten and Jones (1995)

Willmert (1984)

Tuten and Jones (1995)

Tuten and Jones (1995)

Welwood (1977)

Mulliner (1986)

Tuten and Jones (1995)

Tuten and Jones (1995)

Copeland and Mundle (2002)

McGrath (1967)

Tuten and Jones (1995)

Bourgeois et al. (1998)

Tuten and Jones (1995)

Tuten and Jones (1995)

Tuten and Jones (1995)

Tuten and Jones (1995)

Tuten and Jones (1995)

Tuten and Jones (1995)

Tuten and Jones (1995)

Tuten and Jones (1995)

Ellsworth (1942)

Schmitz-Veltin (1984)

Tuten and Jones (1995)

McGrath (1975) 


\section{Institution}

University of Stellenbosch

University of Texas

University of Wichita

Washburn University

Western Washington University

Youngstown State University

\section{Data Sources}

Allen, G. G., and Lee Ching Tat. "The Development of an Objective Budget Allocation Procedure for Academic Library Acquisitions." Libri 37, no. 3 (Sept. 1987): 211-21.

Association of Research Libraries. The Allocation of Materials Funds in Academic Libraries. SPEC Kit 36 (Washington, D.C.: Association of Research Libraries, 1977).

Bourgeois, Eugene, et al. "Faculty-Determined Allocation Formula at Southwest Texas State University." Collection Management 23, no. 1/2 (1998): 113-23.

Brookshier, Doris, and Nancy E. Littlejohn. "Resource Allocation within an Automated Fund Accounting System." In Proceedings, Acquisitions '90 Conference on Acquisitions, Budgets, and Collections, ed. David C. Genaway, 45-55 (Canfield, Ohio: Genaway and Assoc., 1990).

Brownson, Charles W. "Modeling Library Materials Expenditure: Initial Experiments at Arizona State University." Library Resources \& Technical Services 35, no. 1 (Jan. 1991): 87-103.

Budd, John M., and Kay Adams. "Allocation Formulas in Practice." Library Acquisitions: Practice of Theory 13, no. 4 (Winter 1989): 381-90.

Coney, Donald. "An Experimental Index for Apportioning Departmental Book Funds for a University Library.” Library Quarterly 12, no. 3 (July 1942): 422-28.

Copeland, Lynn, and Todd M. Mundle. "Library Allocations: Faculty and Librarians Assess 'Fairness." portal: Libraries and the Academy 2, no. 2 (Apr. 2002): 267-76.

Donlan, Rebecca. "How Much Does Biology Really Need, Anyway? Determining Library Budget Allocations.” Library Issues 26, no. 6 (July 2006): 1-4.

Ellsworth, Ralph E. "Some Aspects of the Problem of Allocating Book Funds among Departments in Universities." Library Quarterly 12, no. 3 (July 1942): 486-94.

Falley, Eleanor, W. "An Impersonal Division of the College Book Fund.” Library Journal 64, no. 21 (Dec. 1, 1939): 933-35.

Genaway, David C. "The Q Formula: The Flexible Formula for Library Acquisitions in Relation to the FTE Driven Formula." Library Acquisitions: Practice \& Theory 10, no. 4 (Winter 1986): 293-306.

Graf Eckbrecht von Dürckheim-Montmartin, Max E., et al. "Library Materials Fund Allocation: A Case Study." Journal of Academic Librarianship 21, no. 1 (Jan. 1995): 39-42.

Greaves, F. Landon, Jr. The Allocation Formula As a Form of Book Fund Management in Selected State-Supported Academic Libraries. Ph.D. dissertation, Florida State Univ., 1974.

Hekhuis, L. "A Formula for Distribution of Library Funds among Departments." Library Journal 61, no. 14 (Aug. 1936): $574-75$.

\section{Source}

Graf Eckbrecht von Dürckheim-Montmartin et al. (1995)

Coney (1942)

Hekhuis (1936)

Tuten and Jones (1995)

Packer (1988)

Genaway (1986)

Jones, Plummer Alston, Jr., and Connie L. Keller. "From Budget Allocation to Collection Development: A System for the Small College Library." Library Acquisitions: Practice \& Theory 17, no. 2 (Summer 1993): 183-89.

McGrath, William E. "Determining and Allocating Book Funds for Current Domestic Buying." College \& Research Libraries 28, no. 3 (July 1967): 269-72.

. "A Pragmatic Book Allocation Formula for Academic and Public Libraries with a Test for Its Effectiveness." Library Resources \& Technical Services 19, no. 4 (Fall 1975): 356-69.

Mulliner, Kent. "The Acquisition Allocation Formula at Ohio University." Library Acquisitions: Practice \& Theory 10, no. 4 (Winter 1986): 315-27.

Niemeyer, Mollie, et al. "Balancing Act for Library Materials Budgets: Use of a Formula Allocation." Technical Services Quarterly 11, no. 1 (1993): 43-60.

Packer, Donna. "Acquisitions Allocations: Equity, Politics, and Formulas." Journal of Academic Librarianship 14, no. 5 (Nov. 1988): 276-86.

Rein, Laura O., et al. "Formula-Based Subject Allocation: A Practical Approach.” Collection Management 17, no. 4 (1993): 25-48.

Richards, James H., Jr. "Allocation of Book Funds in College Libraries." College \& Research Libraries 14, no. 4 (Oct. 1953): 379-80.

Schmitz-Veltin, Gerhard. "Literature Use As a Measure for Funds Allocation.” Trans. John J. Boll. Library Acquisitions: Practice \& Theory 8, no. 4 (Winter 1984): 267-74.

Scudder, Mary C. "Using Choice in an Allocation Formula in a Small Academic Library.” Choice 24, no. 10 (June 1987): 1506-11.

Tuten, Jane H., and Beverly Jones, eds. Allocation Formulas in Academic Libraries, CLIP Note 22 (Chicago: Association of College \& Research Libraries, 1995).

Welwood, Ronald J. "Book Budget Allocations: An Objective Formula for the Small Academic Library." Canadian Library Journal 34, no. 3 (June 1977): 213-19.

Willmert, John Allen. "College Librarians and Professors: Partners in Collection Building and Fund Allocation." In Academic Libraries: Myths and Realities, ed. Suzanne C. Dodson and Gary L. Menges, 293-97 (Chicago: Association of College \& Research Libraries, 1984). 


\section{Appendix B. Data Used in the Example Analyses}

\begin{tabular}{|c|c|c|c|c|c|c|c|c|}
\hline Department & $a$ & $t$ & c & e & $\mathrm{h}$ & $f$ & $\mathrm{~m}$ & $p$ \\
\hline African Studies & 3.05 & 232 & 9 & 85 & 0 & 0 & 0 & 54.02 \\
\hline Anthropology & 2.50 & 678 & 23 & 415 & 3 & 4 & 11 & 50.18 \\
\hline Asian Studies & 2.33 & 1004 & 24 & 0 & 1 & 0 & 0 & 49.72 \\
\hline Biology & 4.73 & 1122 & 34 & 603 & 29 & 11 & 91 & 50.43 \\
\hline Canadian Studies & 3.17 & 244 & 10 & 77 & 0 & 3 & 1 & 39.80 \\
\hline Chemistry & 5.28 & 248 & 19 & 412 & 3 & 6 & 15 & 68.64 \\
\hline Economics & 4.33 & 1082 & 29 & 1045 & 10 & 9 & 95 & 56.91 \\
\hline Education & 2.27 & 946 & 88 & 1169 & 1 & 13 & 48 & 34.86 \\
\hline English & 6.47 & 2432 & 62 & 1270 & 15 & 21 & 118 & 50.52 \\
\hline Environmental Studies & 2.82 & 886 & 36 & 430 & 3 & 5 & 40 & 47.35 \\
\hline Fine Arts & 7.04 & 1028 & 41 & 653 & 1 & 7 & 43 & 72.02 \\
\hline French & 2.50 & 130 & 10 & 213 & 1 & 4 & 1 & 43.82 \\
\hline Gender Studies & 2.96 & 662 & 27 & 164 & 0 & 1 & 0 & 39.60 \\
\hline Geology & 3.96 & 160 & 22 & 241 & 6 & 5 & 24 & 76.43 \\
\hline German & 2.00 & 164 & 8 & 76 & 0 & 2 & 2 & 38.02 \\
\hline Global Studies & 5.00 & 694 & 56 & 344 & 3 & 5 & 16 & 62.69 \\
\hline Government & 6.33 & 1528 & 33 & 1035 & 26 & 10 & 99 & 52.90 \\
\hline History of Science & 1.00 & 280 & 0 & 0 & 0 & 0 & 0 & 50.86 \\
\hline History & 4.75 & 2388 & 54 & 794 & 3 & 10 & 75 & 45.63 \\
\hline Italian & 0.58 & 50 & 2 & 52 & 0 & 1 & 0 & 42.98 \\
\hline Japanese & 1.96 & 54 & 2 & 35 & 0 & 1 & 0 & 47.64 \\
\hline Latin American Studies & 0.90 & 326 & 25 & 63 & 0 & 0 & 0 & 58.61 \\
\hline Mathematics & 2.04 & 1082 & 43 & 1321 & 20 & 12 & 71 & 55.93 \\
\hline Music & 3.30 & 458 & 30 & 294 & 1 & 3 & 8 & 48.10 \\
\hline Philosophy & 1.67 & 688 & 24 & 377 & 3 & 4 & 5 & 49.32 \\
\hline Physics & 1.29 & 514 & 17 & 231 & 1 & 5 & 11 & 50.60 \\
\hline Psychology & 2.92 & 546 & 27 & 1302 & 26 & 12 & 146 & 57.83 \\
\hline Religious Studies & 4.17 & 1076 & 17 & 403 & 1 & 4 & 12 & 34.36 \\
\hline Russian & 0.34 & 132 & 0 & 0 & 0 & 0 & 0 & 49.13 \\
\hline Sociology & 3.54 & 1926 & 32 & 686 & 11 & 9 & 48 & 49.15 \\
\hline Spanish & 2.50 & 124 & 11 & 267 & 3 & 4 & 15 & 75.97 \\
\hline Speech and Theatre & 1.46 & 576 & 37 & 452 & 1 & 7 & 23 & 50.19 \\
\hline Sports and Athletics & 0.83 & 162 & 21 & 442 & 0 & 8 & 0 & 48.53 \\
\hline
\end{tabular}

Notes: Each row represents a particular academic department. Variable a is the previous year's fund allocation — the percentage of the firm order budget allocated for materials acquired in support of each department or program during the 2004-05 academic year. See table 1 for descriptions of the other variables. 